\title{
The Study of Noise Pollution Caused by Birjand Airport on the Surrounding Residents
}

MortezaAraghi* and Mohammad Mehdi Yaghobi

Civil Engineering, University of Birjand, Birjand, Iran; m.araghi@birjand.ac.ir, yaqubig@gmail.com

\begin{abstract}
Today, there are some airports in urban areas that cause adverse environmental impacts on the human body health and psychological behaviors. In order of extending the airport traffic in urban areas it is necessary to control in such manner to prevent the increasing this effects and decreasing it. This project examines the effects of noise pollution on residents of Birjand airport airline area. Nowadays, with the development of the city of much building and redirected its flights, the more residential areas are affected by airline noise. This research has application purpose which the work is of Collection descriptive Study as the data were taken at specific of time the cross sectional study has been used. In this study, the study area by using the map of the city and close to the field and to see the impact of road traffic is divided into two regional aircraft, and for this purpose the 144 questionnaire by using the Morgan table distributed in 500 peoples residing in those areas were analyzed. The results represents the influences of noise pollution with the distance region in second place (for example, in the case of Sleep disorders, approximately $16.6 \%$ ) reduced. The sleep disorders (55.57\% of the population) have the most adverse impact on residents over these areas and the others parameter such as stress, nervous mode and mental illness does not come as a factor of the influence.
\end{abstract}

Keywords: Airports, Physical and Mental Health, Noise Pollution

\section{Introduction}

Today, there are some airports in urban areas caused the environmental undesired impacts and adverse effects on physical and mental health of human beings, exposure to aircraft noise associated with physiological responses and psychological reactions such as sleep disorders, irregular breathing during sleep, nervousness and annoyance ${ }^{1-3}$. However, based on the amount of exposure to aircraft noise, increases the risk of side effects such as heart health, high blood pressure ${ }^{4-8,12}$ and lead to the frequent use of antihypertensive drugs ${ }^{1,9,10-11}$.

According to previous studies conducted on airport noise pollution on the surrounding residents investigates their results, a study that examines the impact of aircraft noise on public health of residents ( $25 \mathrm{~km}$ radius) around Amsterdam Schimpol Airport is determined that there is a significant relationship between the exposure of the population and the use of hypnotic and sedative drugs and cardiovascular drugs and the frequent use, ${ }^{13}$ as well as a study on the residents of the surrounding area Kunsam military airport in the Republic of Korea divided into three groups depending on their distance and between 30 and 79 years of age, it was given $45.5 \%$ of the control group and 8.71 of the group exposed to low noise and 1.77 groups exposed to noise during sleep were more impaired ${ }^{14}$, another study on the risk of mental disorders caused by aircraft noise in the Gillaques area in vicinity of the airport Elmas (Sardinia, Italy), shows the long-term anxiety among the people in those areas ${ }^{15}$.

Also according to research by Professor Stansfald, noise pollution causes sleep disorders, cardiovascular disease and mental disorders and hearing loss in children ${ }^{16}$. In another study showed that the children near the air-

${ }^{*}$ Author for correspondence 
port in London for every increase $5 \mathrm{~dB}$ above normal noise, average two months are back in reading than their classmates, more than any other, the research was also considered different social and economic ${ }^{17}$. For this purpose, according to the development of aircraft traffic in urban areas must be control the impacts of this in order to reduce their effects, noise pollution caused by takeoff and landing aircraft as it passed over the city around an area about 100 square kilometers affect around major airports that known as largest sound pollution, so that the aircraft is sitting its height become less than 60 meters make sound more than $100 \mathrm{~dB}$ if the standard residential areas, $55 \mathrm{~dB}$ at day and $45 \mathrm{~dB}$ at night 18 . And where the planes should be landing with angle $3^{\circ}$ at a height of 60 meters at a distance of 1,200 meters from the runway this area is usually outside the airport, but the subject is Birjand Airport 2300 meters distance from residential areas, however, also has its own effects.

In view of the airport was established in 1312 and at that time its distance to the city was proper, is not much pollution, but today, with the expansion of the city and the construction as well as redirect the runway that passes more flights from residential areas residents of areas affected by noise caused by their flights and in this project, we examined the effects of noise pollution airlines in Birjand airport on residents around it.

\section{Theoretical Foundations}

Research in this research is named; most of them sound intensity in every 250 to 250 square meters calibrated measuring device of sound, for the area surrounding the

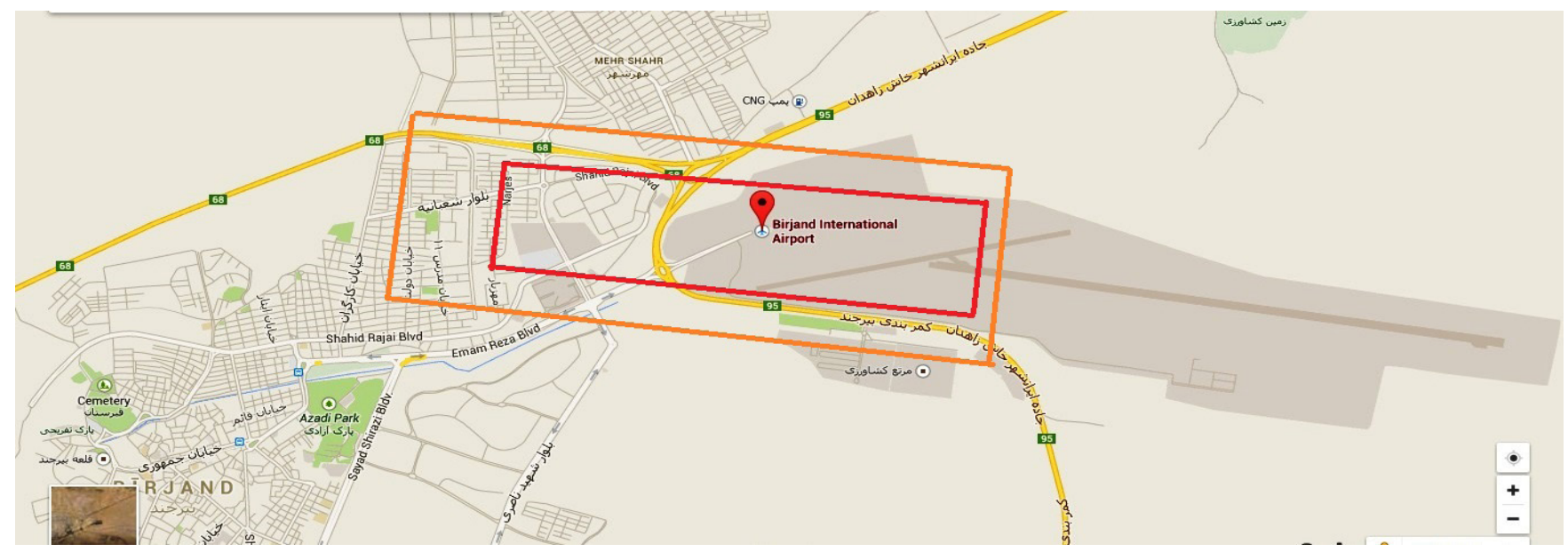

airport, with an accuracy of $1 \mathrm{db}$ measured, and residents around the airport have zoning on the intensity; in this study, the effects of aircraft noise on nearby residents have been made in the following ways:

1. Using the questionnaire: the questionnaire with the suitable reliability and validity study for understanding the effects (such as psychological factors affecting human physiological, stress and etc use in resources ${ }^{2-4,10,15-16}$ have been used.

2. The use of tests: tests that measure indicators related to the level of some of the parameters (blood pressure, stress, etc.) is done in the laboratory, such as the release of stress hormones (like cortisol in saliva), which increases the risks of cardiovascular and blood pressure in people. In the source ${ }^{1}$ this method is used, showed that cortisol levels in women exposed to noise above $60 \mathrm{~dB}$ vs. women exposed to noise lower than are at the higher and more significant level.

3. Use the verbal observation: This is observed for some parameters such as measuring blood pressure and the use of hypnotic and sedative drugs in residents around the airport (sources such as ${ }^{10-11,13}$ has been used this method).

\section{Problem Definition and Objectives of Research}

There are currently 15 flights a week on routes Birjand, Tehran - Birjand - Mashhad, Birjand - Damascus, Birjand - Medina, Birjand - Baghdad that used aircraft for these routes is the Fokker 10 and MD, Boeing 727, Airbus 300

Figure 1. Aerial maps around the airport and its zoning. 
and Tupolev 154 that two Fokker 100 and MD, both at the same time with the low ability of air carriers have high noise and environmental pollution.

The aim of this study is to evaluate the effect of noise pollution from Birjand airport on resident's physical and mental health, the question has been raised as, according to your vicinity to Birjand Airport, each of the factors (sleep disorders, nervousness, stress and mental illness and disturbance of the speech) how much impacted your health and those around, the questionnaire to quantify (including options that come with 0 to 4 ) to review each factor and verified by experts as well as through a crowd of 500 people living in those areas, according to Morgan and 144 of these questionnaires on 29/12/2013 and $19 / 01 / 2014$ were distributed in the study area; the two regions based on their distance from the airport, using field reports and aerial maps of the city as seen in Figure 1 , is separated.

Areas such as Shabanieh Boulevard and Narjes part of Zone 1, areas including Mehrshahr and Doulat Street part of Zone 2 that the aircraft are further away; the share of each of these areas was 72 questionnaires. Study type is descriptive survey that carried out in a given time period, and because of cross-sectional data collection was used and has applied expression that using the answers given by the people of those areas and analysis results by spss software are as follows:

\section{Analysis}

Initially, the descriptive statistics for the variables analyzed. Table 1, shows two middle and indicator for the variables which the number of questionnaire are the same in both zone in the zone and for front is equal to 1 (smaller number) was taken. According to Table 1, because it can be said that the coefficient zero has minimum frequency for each variable overall noise pollution in both area has the least impact on the variables.

According to Table 2 can said that least and most percent of responses about sleep disorders variable related to coefficients of one and zero, respectively and about the nervous state variable, can said that least and most percent of responses related to coefficients of three and zero respectively, also for the variable stress and mental illness least percent of responses related to coefficients of three and most percent of responses related to coefficients of zero, about the conflict in the speech least percent of responses related to coefficients of two and most percent of responses related to coefficients of zero. Note that in all cases coefficients of zero was allocated lowest percent of responses and this result clearly with the results in Table 1 related to the indicators described is consistent.

For closer examination of the relationships between variables and to better assess the effects of noise pollution from Birjand airport statistical tests used. Thus, in each case, the independence test between variables using the correspondence tables is done.

Table 3 shows the results of independence test between zone and sleep disorders, between zone and nervousness, between zone and stress and mental illness, between zone and interference in speech. According to the table assumes the independence between these two variables and sleep disorders rejected and that means that the noise pollution caused by Birjand Airport effect on individual's sleeping and independence between zone and nervousness since the p-value is equal to 0.138 the assumption of independence between these variables is accepted.

Table 1. Descriptive statistic indicators of variables

\begin{tabular}{|c|c|c|c|c|c|c|}
\hline \multicolumn{2}{|c|}{} & Zone & Sleep disorders & Nervousness & Stress and mental illness & Interference in speech \\
\hline \multirow{2}{*}{$\mathrm{N}$} & Valid & 144 & 144 & 144 & 144 & 144 \\
\cline { 2 - 7 } & Missing & 0 & 0 & 0 & 0 & 0 \\
\hline \multirow{2}{*}{ Median } & & 1.0000 & .0000 & .0000 & .0000 \\
\hline \multicolumn{2}{|c|}{ Mode } & $1.00^{\mathrm{a}}$ & .00 & .00 & .00 & .00 \\
\hline
\end{tabular}


Table 2. Percentage of discontent both in the zone of each of the variables

\begin{tabular}{|c|c|c|c|c|c|c|}
\hline \multirow{7}{*}{ Sleep disorders } & & & Frequency & Percent & Valid Percent & Cumulative Percent \\
\hline & \multirow{6}{*}{ Valid } & .00 & 64 & 44.4 & 44.4 & 44.4 \\
\hline & & 1.00 & 12 & 8.3 & 8.3 & 52.8 \\
\hline & & 2.00 & 14 & 9.7 & 9.7 & 62.5 \\
\hline & & 3.00 & 26 & 18.1 & 18.1 & 80.6 \\
\hline & & 4.00 & 28 & 19.4 & 19.4 & 100.0 \\
\hline & & Total & 144 & 100.0 & 100.0 & \\
\hline \multirow{7}{*}{ Nervousness } & & & Frequency & Percent & Valid Percent & Cumulative Percent \\
\hline & \multirow{6}{*}{ Valid } & .00 & 90 & 62.5 & 62.5 & 62.5 \\
\hline & & 1.00 & 14 & 9.7 & 9.7 & 72.2 \\
\hline & & 2.00 & 12 & 8.3 & 8.3 & 80.6 \\
\hline & & 3.00 & 10 & 6.9 & 6.9 & 87.5 \\
\hline & & 4.00 & 18 & 12.5 & 12.5 & 100.0 \\
\hline & & Total & 144 & 100.0 & 100.0 & \\
\hline \multirow{7}{*}{$\begin{array}{c}\text { Stress and } \\
\text { mental illness }\end{array}$} & & & Frequency & Percent & Valid Percent & Cumulative Percent \\
\hline & \multirow{6}{*}{ Valid } & .00 & 78 & 54.2 & 54.2 & 54.2 \\
\hline & & 1.00 & 18 & 12.5 & 12.5 & 66.7 \\
\hline & & 2.00 & 16 & 11.1 & 11.1 & 77.8 \\
\hline & & 3.00 & 14 & 9.7 & 9.7 & 87.5 \\
\hline & & 4.00 & 18 & 12.5 & 12.5 & 100.0 \\
\hline & & Total & 144 & 100.0 & 100.0 & \\
\hline \multirow{7}{*}{$\begin{array}{c}\text { Interference in } \\
\text { speech }\end{array}$} & & & Frequency & Percent & Valid Percent & Cumulative Percent \\
\hline & \multirow{6}{*}{ Valid } & .00 & 82 & 56.9 & 56.9 & 56.9 \\
\hline & & 1.00 & 24 & 16.7 & 16.7 & 73.6 \\
\hline & & 2.00 & 6 & 4.2 & 4.2 & 77.8 \\
\hline & & 3.00 & 12 & 8.3 & 8.3 & 86.1 \\
\hline & & 4.00 & 20 & 13.9 & 13.9 & 100.0 \\
\hline & & Total & 144 & 100.0 & 100.0 & \\
\hline
\end{tabular}

Therefore, based on these data cannot be claimed that the noise pollution impact on resident's nervousness, as well as the independence between zone and stress and mental illnesses, given the $\mathrm{p}$-value is equal to 0.103 (more than 0.50 ) the assumption of independence between both variable accepted and means that existing data cannot be claimed the noise pollution effect on stress and mental diseases because their response do not related to place of residence and output related to test the independence of two zones and interference with speech can be concluded with respect to $\mathrm{P}$-value the assumption of independence between these two variables will be accepted. Therefore, based on these findings, since the individuals response to variable interfere in speech, do not related to the residential area, it cannot be claimed that the noise pollution from the airport have an effect on the speech of individuals.

The Figure 2 represents the individual's response to coefficients related to sleep disorders, graphs (2) related to nervousness, graphs (3) stress and mental illness Figure 5 related to interference in speech (according to zone ).

According to the results obtained from the analysis of the results of this study, the noise pollution from Birjand airport just disturbed resident's sleep. 
Table 3. Independence between noise pollution and each variable

\begin{tabular}{|c|c|c|c|c|c|}
\hline \multirow{3}{*}{$\begin{array}{l}\text { Zone and Sleep } \\
\text { disorders }\end{array}$} & & Value & Asymp. Std. Error ${ }^{\mathrm{a}}$ & Approx. $\mathrm{T}^{\mathrm{b}}$ & Approx. Sig. \\
\hline & Gamma & -.475 & .146 & -2.995 & .003 \\
\hline & $\mathrm{N}$ of Valid Cases & 144 & & & \\
\hline \multirow{3}{*}{$\begin{array}{l}\text { Zone and } \\
\text { Nervousness }\end{array}$} & & Value & Asymp. Std. Error ${ }^{\mathrm{a}}$ & Approx. $\mathrm{T}^{\mathrm{b}}$ & Approx. Sig. \\
\hline & Gamma & -.296 & .192 & -1.483 & .138 \\
\hline & $\mathrm{N}$ of Valid Cases & 144 & & & \\
\hline \multirow{3}{*}{$\begin{array}{l}\text { Zone and Stress and } \\
\text { mental illness }\end{array}$} & & Value & Asymp. Std. Error ${ }^{a}$ & Approx. $T^{b}$ & Approx. Sig. \\
\hline & Gamma & -.295 & .176 & -1.632 & .103 \\
\hline & $\mathrm{N}$ of Valid Cases & 144 & & & \\
\hline \multirow{3}{*}{$\begin{array}{l}\text { Zone and Interference } \\
\text { in speech }\end{array}$} & & Value & Asymp. Std. Error ${ }^{\mathrm{a}}$ & Approx. $T^{b}$ & Approx. Sig. \\
\hline & Gamma & -.084 & .195 & -.429 & .668 \\
\hline & $\mathrm{N}$ of Valid Cases & 144 & & & \\
\hline
\end{tabular}

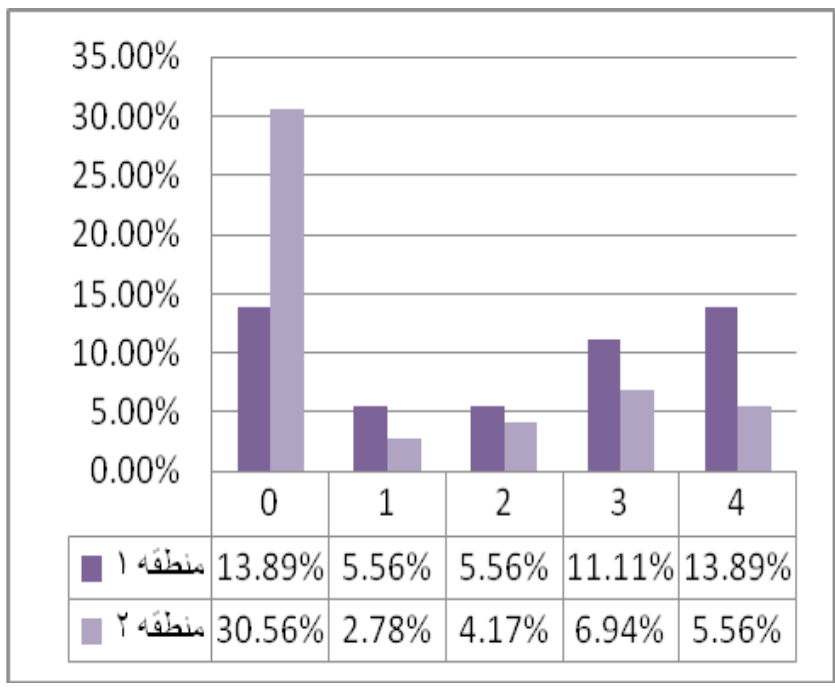

Figure 2. Sleep disorders (according to zone)

\section{Discussion}

By analyzing the responses on noise pollution from Birjand airport on the surrounding residents, we can conclude that:

1. The effects of noise pollution in the zone 2 by distance is reduced, so that 55.57 percent of the population suffered from sleep disorders 36.12

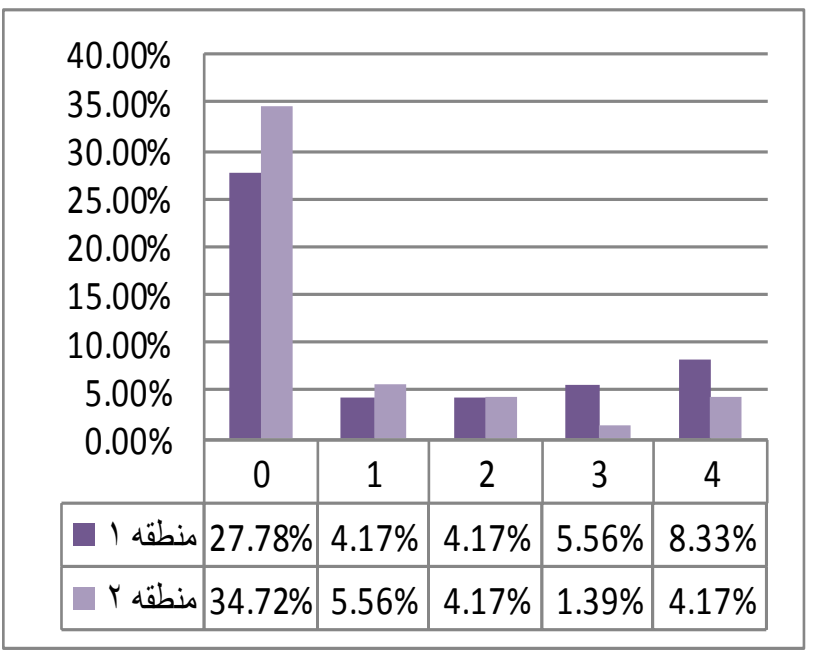

Figure 3. Nervousness (according to zone)

percent in zone 1 and 19.45 percent in zone 2, as well as $37.52 \%$ of people with nervousness conditions 22.23 percent living in zone 1 and 15.29 per cent have been living in zone 2 and as well as $45.83 \%$ of people with stress and mental illness that 27.77 percent living in zone 1 and 18.06 percent of those in zone 2 will eventually $43.05 \%$ of the people suffered of interference in speech, that 


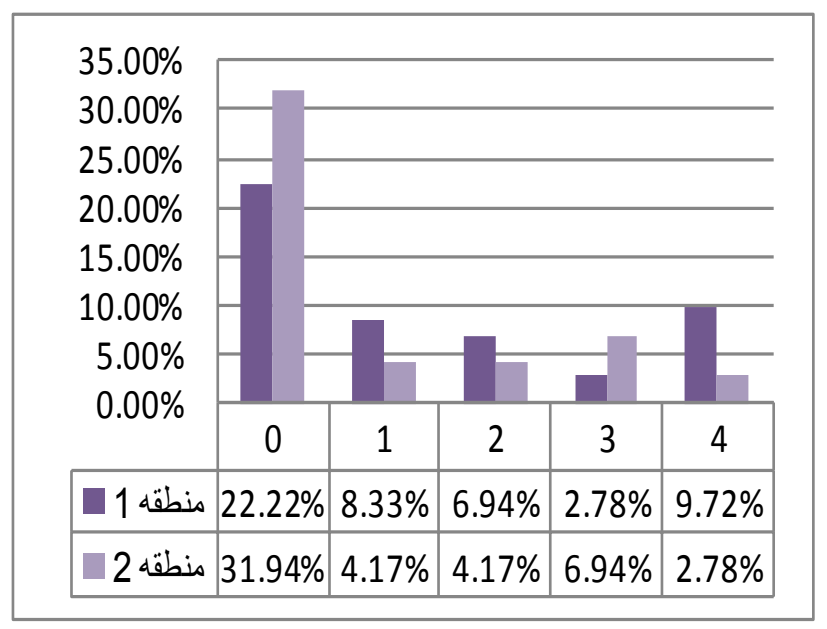

Figure 4. Stress and mental illnesses (according to zone)

22.22 percent living in zone 1 and 20.83 percent living in zone 2.

2. Noise pollution from Birjand airport affected people's sleep so that $55.57 \%$ of people beilived that their sleep by the noise of aircraft, is impaired.

3. Two variables nervousness and zone are independent of each other ( $\mathrm{p}$-value $=0.138>0.05$ ) and cannot be claimed noise pollution affected the resident's nervousness condition.

4. noise pollution, stress and mental illness those zones ( $\mathrm{p}$-value $=0.103>0.05$ ) was not effective.

5. Interference in speech variable is not dependence on the residential zone ( $\mathrm{p}$-value $=0.668>0.05)$.

6. Overall in both zone, noise pollution has the least impact on the variables.

\section{Conclusion}

In this paper, the effects of noise pollution of Birjand airlines on residents around it investigated, by analyzing the data found that the effects of noise pollution by distance in the zone 2 reduced, the noise pollution from Birjand airport affects sleep mode and will not affect nervousness, stress and mental illness and interfere with speech; however, due to the effects of noise pollution caused by aircraft noise on sleep of those living in these areas can be insulated components of office and residential building to reduce noise and limited-time takeoff and landing aircraft, especially at night (10 to $8 \mathrm{am}$ ) used.

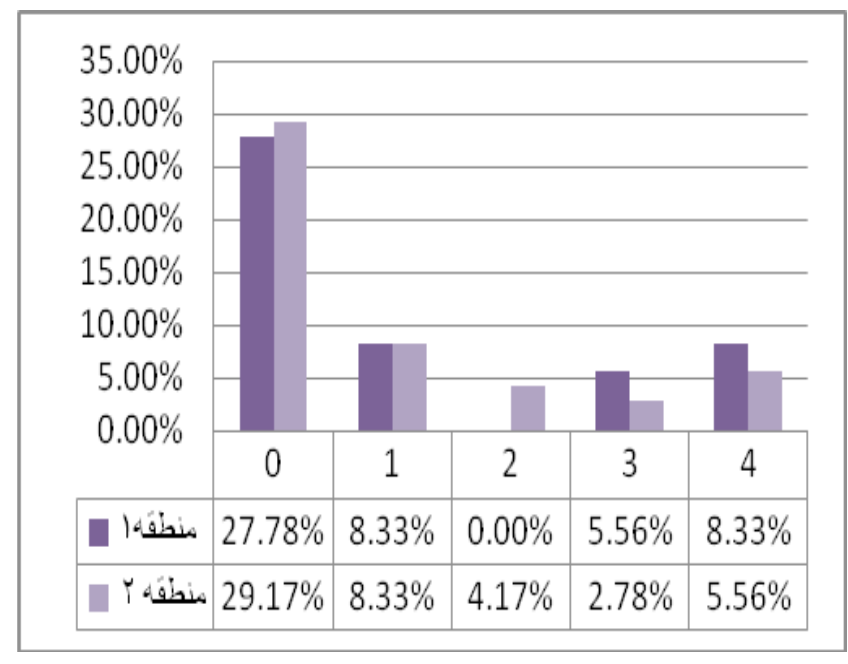

Figure 5. Interference in speech (the separation zone)

\section{References}

1. Bluhm G, Eriksson C. Cardiovascular effects of environmental noise: research in Sweden. Noise Health. 2011; 13:212-6.

2. Hatfield J, Job R, Carter NL, Peploe P, Taylor R, Morrell $\mathrm{S}$. The influence of psychological factors on self-reported physiological effects of noise. Noise Health. 2001; 3:1-13.

3. Rosenlund M, Berglind N, Pershagen G, Jarup L, Bluhm G. Increased prevalence of hypertension in a population exposed to aircraft noise. Occup Environ Med. 2001; 58:769-73

4. Eriksson C, Bluhm G, Hilding A, Ostenson CG, Pershagen G. Aircraft noise and incidence of hypertension - gender specific effects. Environ Res. 2010; 110:764-72.

5. Haralabidis AS, Dimakopoulou K, Vigna-Taglianti F, Giampaolo M, Borgini A, Dudley ML, et al. Acute effects of night-time noise exposure on blood pressure in populations living near airports. Eur Heart J. 2008; 29:658-64.

6. Jarup L, Babisch W, Houthuijs D, Pershagen G, Katsouyanni $\mathrm{K}$, Cadum E, et al. Hypertension and exposure to noise near airports: the HYENA study. Environ Health Perspect. 2008; 116:329-33.

7. Haralabidis AS, Dimakopoulou K, Velonaki V, Barbaglia G, Mussin M, Giampaolo M, et al. Can exposure to noise affect the $24 \mathrm{~h}$ blood pressure profile? Results from the HYENA study. J Epidemiol Community Health. 2011; 65:535-41.

8. Matsui T, Uehara T, Miyakita T, Hiramatsu K, Yasutaka O, Yamamoto T. The Okinawa study: effects of chronic aircraft noise on blood pressure and some other physiological indices. J Sound Vib. 2004; 277:469-70.

9. Greiser E, Janhsen K, Greiser C. Air traffic noise increases prescriptions of cardiovascular drugs in the vicinity of a 
major airport. Epidemiology. 2007; 18:S33.

10. Franssen EA, van Wiechen CM, Nagelkerke NJ, Lebret E. Aircraft noise around a large international airport and its impact on general health and medication use. Occup Environ Med. 2004; 61:405-13.

11. Floud S, Vigna-Taglianti F, Hansell A, Blangiardo $M$, Houthuijs D, Breugelmans O, et al. Medication use in relation to noise from aircraft and road traffic in six European countries: results of the HYENA study. Occup Environ Med. 2011; 68:518-24.

12. Babisch W, Kim R. Environmental noise and cardiovascular disease. In: WHO European Centre for Environmental Health, ed. Burden of disease from environmental noise: Quantification of healthy life years lost in Europe. World Health Organization; 2011; 15-44.

13. Franssen E, van Wiechen CMAG, Nagelkerke N, Lebret E. Aircraft noise around a large international airport and its impact on general health and medication use. Occup Environ Med. 2004 May; 61(5):405-13.

14. Yoon JH, Hong JS, Roh J, Kim CN, Won JU. Dose - response relationship between noise exposure and the risk of occupational injury. Noise Health. 2015; 17:43-7.

15. Hardoy MC, Carta MG, Marci AR, Carbone F, Cadeddu M, Kovess V, Dell'Osso L, Carpiniello B. Exposure to aircraft noise and risk of psychiatric disorders: the Elmas surveyaircraft noise and psychiatric disorders. Social Psychiatry and Psychiatric Epidemiology. 2005; 40(1):24.

16 Stansfeld SA, Matheson MP. Noise pollution: non-auditory effects on health. Br Med Bull. 2003; 68:243-57.

17. Crook MA, Langdon FJ. The effects of aircraft noise in schools around London Airport. Journal of Sound and Vibration. 1974; 34:221-32.

18. Mahmoud S, Masumi R. Airport planning and design of the book. Department of Environment; 2003. 